Books, videos, CD-ROMs, DVDs and any other relavent items submitted for a review in the $B D J$ should be addressed to: Kate Maynard, Assistant Editor, British Dental Journal, NPG, 4-6 Crinan Street, London, N1 9XW

\section{Essential microbiology for dentistry (3rd edition)}

\author{
L. Samaranayake \\ UK: Elsevier \\ price $€ 39.99$, pp 363 \\ ISBN 0443100799
}

Following the success of the previous edition, four years on Professor Samaranayake has wisely kept to the format in layout and design that has already made this one of the most readily accessible basic texts for dental undergraduates. The book is divided into six main parts: General Microbiology, Basic Immunology, Microbes of Relevance to Dentistry, Infections of Relevance to Dentistry, Oral Microbiology and Crossinfections and Control.

Each part starts with a summary of the chapters within, how they relate to other sections in the book, and outside sources of information. The reader is introduced to the fundamentals of infectious agents and of the innate and adaptive host defences before encountering infectious agents (bacteria, viruses and fungi) and the diseases they cause. Throughout these sections emphasis is placed on those examples and aspects of particular relevance to the oral cavity and to dentistry which undoubtedly will reinforce the importance of these topics to the most sceptical of dental students.

In Part 5 the book focuses on oral microbiology, starting with the normal flora, followed by chapters covering the microbiology of dental caries, periodontal disease, dentoalveolar infections and oral mucosal and salivary gland infections. Part 6 on cross-infection and control aims to provide a comprehensive summary of the routine infection control regimes required in every dental practice.

This is a book aiming to demonstrate to the dental student that "the discipline of microbiology is intimately woven into the fabric of dentistry and comprises a crucial component of the dental curriculum'.
As before there is liberal use of tables, diagrams and photographs, clearly laid out to reinforce the text and as useful aids to learning in themselves. The text is written in a style that brings the subject matter clearly and straightforwardly to the reader. Each chapter ends with a list of key facts, a short, relatively up-to-date reading list and a new addition in the form of a self-assessment question and answer section which I think is an excellent idea. New material has been added including advances in molecular biology pertaining to infectious disease, bacterial taxonomy and nomenclature, uncultivable bacteria, biofilms, emerging infections including prion diseases, drug-resistant bacteria and the latest US and UK recommendations for infection control procedures. The greatly expanded index provides improved navigation within topics.

Overall this is a very useful introductory textbook which deserves to be included on the reading list for dental undergraduates and one which I will continue to recommend.

R. A. Whiley

\section{Legal aspects of general dental practice}

\begin{tabular}{l}
\hline L. D'Cruz \\
UK: Elsevier \\
price $£ 36.99$, pp 110 \\
ISBN 0443100381 \\
\hline
\end{tabular}

As dental health care professionals, we are serious about the delivery of care within a legal and regulatory framework. If patients seek redress for alleged negligence, or we are the subject of an inquiry, we ask for advice from our indemnity organisation who may instruct someone competent to represent us, namely a lawyer. So why should we read this book? Just as we want to continue to improve our clinical skills, synthesise and evaluate past and present dental literature, then we want to be at least familiar with issues peripheral to mainstream dentistry. Legal aspects of health care law come within this latter category.

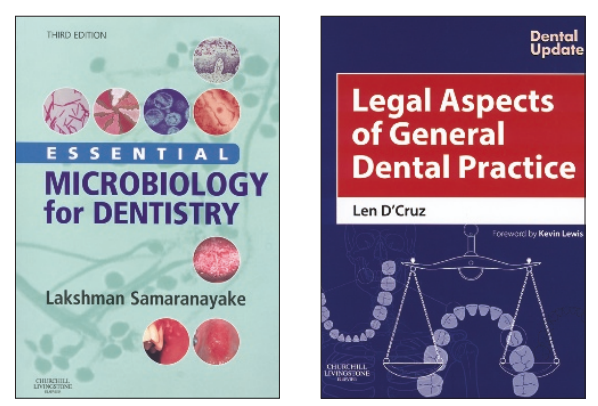

This is a learned book but may be difficult to penetrate (see page $50, \mathrm{X}$ v. $\mathrm{Y}$ ), as some of us have not been trained to explore the logic and nuances of law. However, every effort has been made to make it applicable to our daily care of patients by giving dental illustrations, although not unexpectedly, there is little case law when compared with medicine. For those who want key areas, these are highlighted in blue boxes, familiar to all who read Dental Update.

The book is well structured and comprehensive, with reading lists and references (including websites). Apart for the usual areas you would expect from such a book, there are 'value added' areas such as:

- Chapter 1 - ethical bedrock, branches of law

- Chapter 2 - the folly of using acronyms, implications of The Data Protection Act

- Chapter 3 - a small section tempting the learner to explore the dilemma between 'best interest' test and substituted judgement

- Chapter 4 - confidentiality, illustrated using dental case histories

- Chapter 5 - Mrs Donoghue, the ginger beer float, the decomposing snail illuminating the subject of 'duty of care'

- Appendices - a little on Irish Law and some Scottish issues.

One can always be critical. In the section on the General Dental Council (Chapter 1), it would have been useful to have included advice on whistleblowing ('Principles of raising concerns...'). With the imminent registration of all members of the dental team, there will be an even greater imperative for us all to discharge this responsibility, should there be patient safety issues.

In summary therefore, this book is for all dentists who wish to underpin their present knowledge with an understanding of the area and as a reference book for those preparing for summative examinations $-\mathrm{a}$ bid for six copies has already been placed with my university library. 